\title{
A quartet of intruders
}

— Cite as: CMAJ 2020 January 13;192:E42-3. doi: 10.1503/cmaj.190802

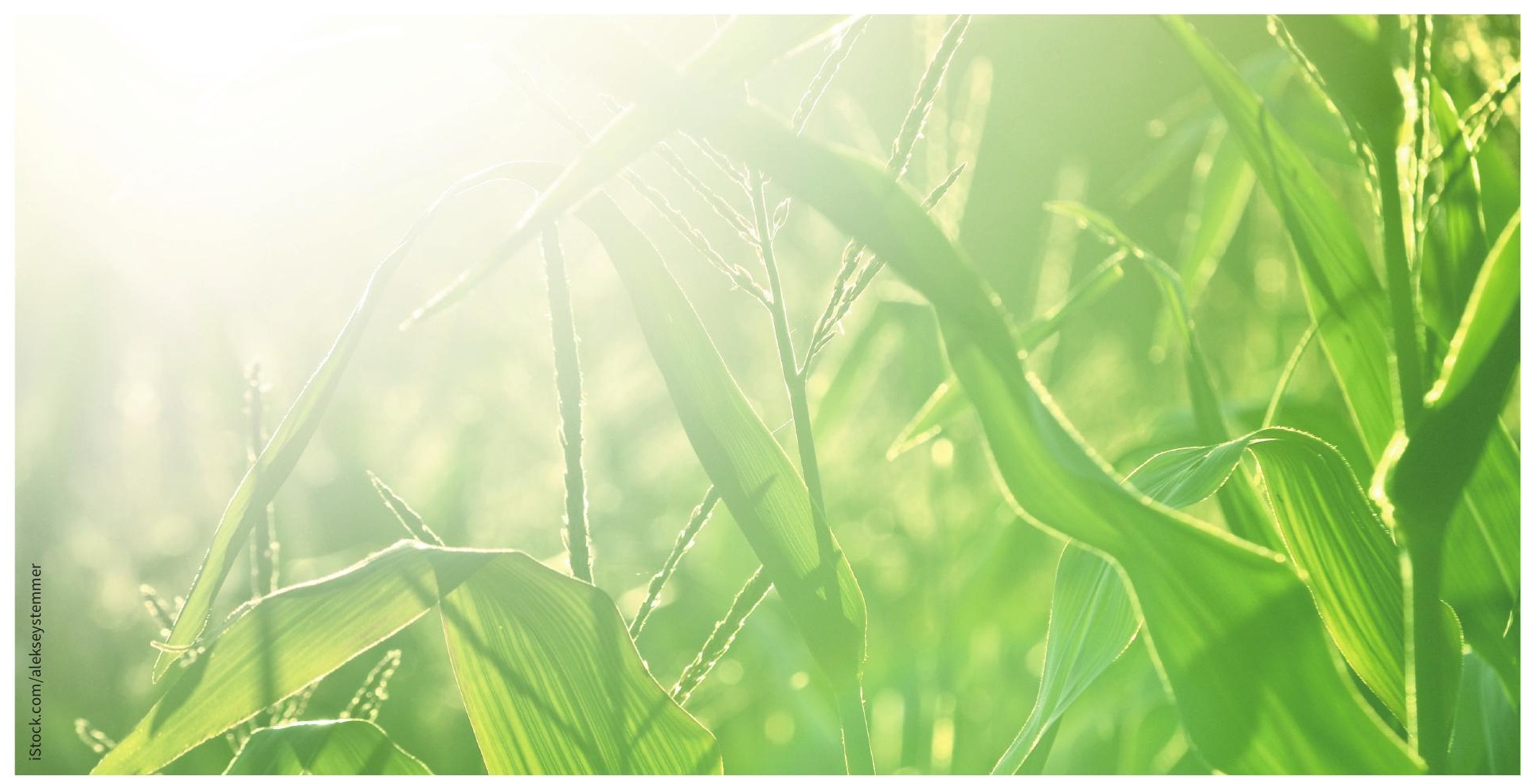

\section{Orange weaver}

We can afford corn, though, starch, binding the precarious diet, mordant, slipknot of the belly crochet.

I run my hands over new folds in the shower, the orange weave hardening, becoming Kevlar under my skin.

I know, from cadavers, how tough this apron is to cut away. Maybe now, knives will bounce off if I'm stabbed.

But what of knives in the blood?

I think, vertiginous, of fat, and risk factors, orange syrup swamping my pancreas, clogging my arteries.

They say salads can sate the weaver, unravel some thread.

We can afford corn, though.

Let us eat corn.

\section{Febrile}

1. Be otherwise kind, but not to this premonition of death.

2. Remember that invaders have chosen to trick this body, and you must intervene from without.

3. Douse, titrate efforts against rate of drop, the hour of the night, and the shiver and cry, bloody-minded.

\section{Hold the line;}

say: "This far, and no further. Now, retreat." 


\section{Dermatosis papulosa nigra}

At a certain age, I began to sprout pangolin scales, a constellation of black under the orbital faceplate, an adaptation to ultraviolence, a radiation of my own spines, discs, spears and shields, the whole body as ward for the eye hamsa, incantation, cowry coat, cower to fend from loss of sight, from galactic lances, a whole body as word for the eye, prophylaxis, pills as manhole covers above the vitreous space of eggs, their nuclear stars, the shelled brain growing into corrugated shield, a dress of roll-up doors for my final evolution: rock, in fire, not burned.

\section{Medical séances}

Acolytes we filed into a darkened temple, luminous film of arcana below the priest figure in front, casting visions overhead. In the projection we learned to listen

for the murmurs of hearts that wanted to speak, and the dead we did not allow to.

After, Pa James, he with the ligature of his hanging still on, was our cadaver. We stripped the gnarly windbreaker of his skin, his fleece of fat, for anatomy. Routinely felled by formalin fumes at night,

it was worse later, in morbid anatomy, too-gleeful residents brandishing sternal saws like bread knives.

All the dead could teach was the fear of life, and how it can end. Benign sturgeons-general, schools in tow, swam us past tufted-ear stingrays but we drowned still, hydrophobic. Resuscitated after medicine, I remember

little but the Latin, an oculus being the grasp of a brain on stalks. Pick your colour. Forgive me, father,

I am not the Esau you sought, with a stethoscope beard to make you proud. Had I listened to spirits of dead doctors who named everything after food - breadand-butter pericardiums, café au lait skin, poma facies

with nutmeg liver, on a cribriform plate you might have liked the meal I made you.

\section{Tolu Oloruntoba MD}

Information Management and Information Technology Services, Provincial Health Services Authority, Burnaby, BC

This article has been peer reviewed. 